International Journal of Current Advanced Research

ISSN: O: 2319-6475, ISSN: P: 2319 - 6505, Impact Factor: SJIF: 5.995

Available Online at www.journalijcar.org

Volume 6; Issue 3; March 2017; Page No. 2752-2754

DOI: http://dx.doi.org/10.24327/ijcar.2017.2754.0098

Research Article

\title{
PROFICIENCY TESTING OF UNDERGRADUATE DENTAL STUDENTSIN PERMANENT TOOTH MORPHOLOGY- A QUESTIONNAIRE BASED STUDY
}

\author{
Trinaina Somas Kandhan., Gifrina Jayraj and K.R.Don
}

Saveetha Dental College and Hospitals, Poonamallee High Road, Chennai.

\begin{tabular}{l}
\hline A R T I C L E I N F O \\
\hline Article History: \\
Received $18^{\text {th }}$ December, 2016 \\
Received in revised form $16^{\text {th }}$ January, 2017 \\
Accepted $26^{\text {th }}$ February, 2017 \\
Published online $28^{\text {th }}$ March, 2017
\end{tabular}

Key words:

Tooth morphology, Dental Anatomy, Identification

\begin{abstract}
A B S T R A C T
Background : Tooth morphology and features of individual tooth forms the basis for dentistry and its subjects. Tooth morphology covers topics such as tooth surfaces, identification of each individual tooth using their characteristic features. As known permanent teeth are 32 in number and each tooth has its characteristic features which are essential for tooth identification, inculcating the knowledge regarding these characteristics will assist dental students and help them in achieving a good practice.
\end{abstract}

Aim : To test the knowledge and proficiency about permanent tooth and its morphology among dental students.

Objective : Dental Anatomy is one of the major subjects for under graduate dental students and forms the foundation to their knowledge. A test was conducted for the dental students to test their knowledge about permanent tooth morphology.

Methodology: This was a survey based study, done using an online forum, SurveyPlanet. The survey was circulated amongst undergraduate students in various years of study, in two colleges in Chennai and one in Dubai and 92 responses were collected. From the obtained responses, the results were tallied and evaluated.

Results:From the survey conducted it was noticed that most students were confused on the landmarks of teeth and it's surfaces and it was also noticed that the students were also not clear with a few other other concepts in accordance with tooth morphology.

Conclusions: On an average nearly $40 \%$ of the students who had taken part in the survey were unable to identify the tooth of basis of questions pertaining to their chronology and morphology. This has to be avoided as tooth morphology lays the foundation towards a proficient dentist who is a confident practitioner..

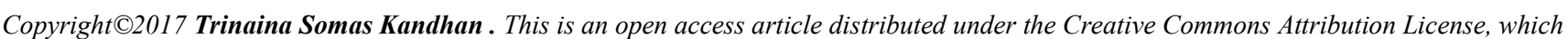
permits unrestricted use, distribution, and reproduction in any medium, provided the original work is properly cited.

\section{INTRODUCTION}

Tooth morphology/dental anatomy is defined as the subject, which deals with the external and internal structure, morphology, function, eruption and shedding of all the teeth in the mouth. [1] Tooth morphology or features of individual tooth forms the basis for dentistry and its subjects. It covers topics such as tooth surfaces, identification of teeth on the basis of specific characteristic features (landmarks, incisal angles, surfaces), chronology of teeth, identification of various different features based on the aspect of each tooth, etc. In most dental colleges, Dental Anatomy is taught as a major subject in the first year of study. Dental anatomy, as a branch of biology, comprises the study and organization of the tooth as an isolated entity and as an integrant of both the

*Corresponding author: Trinaina Somas Kandhan Saveetha Dental College and Hospitals, Poonamallee High Road, Chennai. dental and the masticatory systems [2]. Although anatomy, in general, seems to be a descriptive and static science, dental anatomy escapes from this rule, because it needs to explain the reason for the existence of dynamic functions of the teeth.[2] Teeth, dental arches, and periodontal tissues constitute the major part of most dental practices [2].

The professional (surgeon/dentist) who is committed to the preservation of human teeth should have a clear understanding of the characteristics and fundamentals of dental morphology and must develop enough manual dexterity to reproduce any part of the dental system, maintaining perfect correlation with the whole [2].Of great importance is a knowledge of function and anatomic dental elements, a knowledge that is intimately related to most dental areas [2]. To perform dental procedures with confidence, knowledge pertaining to tooth morphology and dental anatomy is utmost necessary. This survey was conducted amongst undergraduate dental students to analyse whether or not there is clarity in the subject and if there is a lack, in 
which area there is a lack in understanding and how to rectify this lack in clarity, so as to ensure proper understanding to result in confident practice.

\section{METHODS AND MATERIALS}

This study was done by using a survey questionnaire. The survey was conducted on an online forum using SurveyPlanet. It was circulated amongst three colleges, 2 within Chennai and 1 in Dubai, and undergraduate students from the first to fourth year were requested to fill the survey.

A total sample size of 92 responses was received and each response was verified and tallied to arrive at a proper conclusion. In the questionnaire, questions were limited to the mostly the characteristic morphological features of namely, Maxillary Central Incisor, Mandibular First Pre-Molar, Maxillary First molar and Mandibular First Molar. The questions were pertaining to the surfaces, characteristic features and identification of tooth on analysis of the picture and chronological order.

\section{RESULTS}

Out of 92 responses :

5-First year

57-Second year

19-Third year

8- Fourth year

Q4 4. In the picture in the previous question, which surface was displayed 2
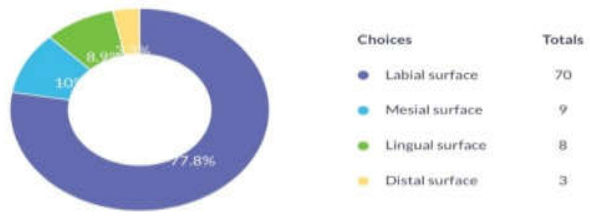

Only $65.2 \%$ of students correctly identified the tooth shown in the picture as maxillary central incisor, however $77.8 \%$ of students correctly identified the surface of the tooth as labial surface.

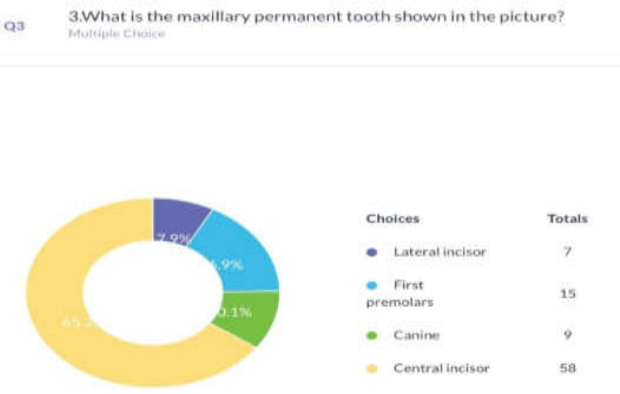

Only $71.9 \%$ of students correctly identified the characteristic feature as sharp mesioincisal angle, this was because most students were confused and chose the option stating rounded mesioincisal.

Q5 5. What is a distinguishing feature of the tooth shown in the picture? \&

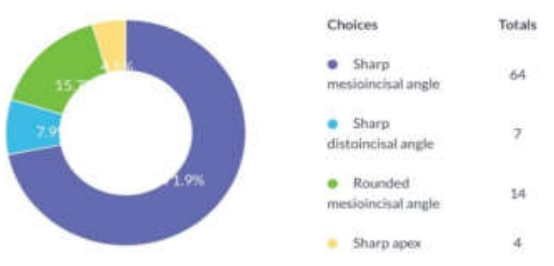

Only $72.2 \%$ of students identified the tooth correctly as Mandibular First Molar on analysis of the chronological order.

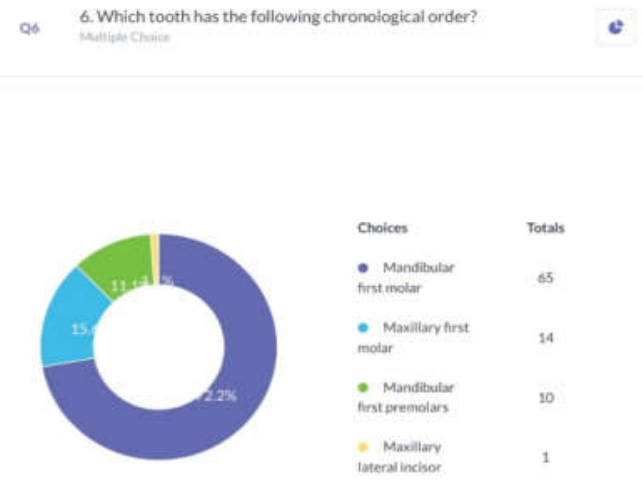

$81.1 \%$ of students identified correctly that the major fossa present in the Maxillary First Molar is only the Central Fossa, most students confused the major fossae present in Mandibular First Molar (Central and Distal Fossae) with this and answered incorrectly.
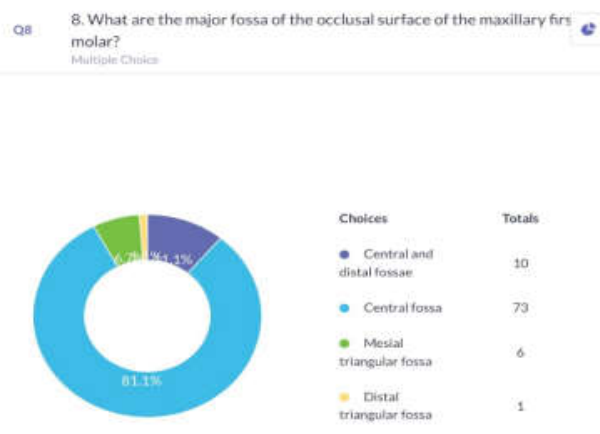

$76.1 \%$ of students answered correctly as Maxillary First Molar on observing the occlusal surface of the picture given. 
Q10 10. Which tooth is shown in the picture?
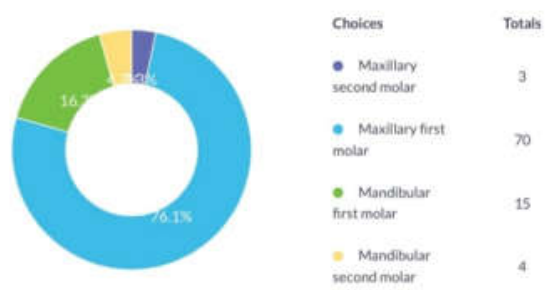

On comparing questions 3 and 10 , it is noted that more students were able to identify the maxillary posterior teeth than the maxillary anterior teeth.

\section{Comparison between data obtained from Question 3 and 10}

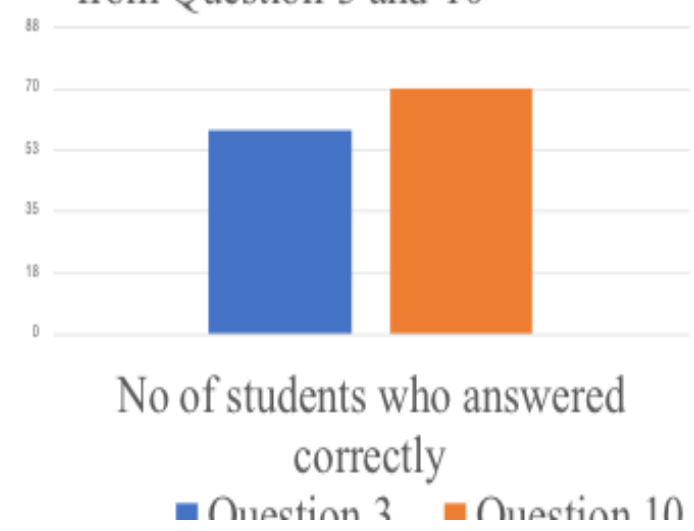

\section{DISCUSSION}

Dental Anatomy is taught as a major subject in the first year of study. Dental anatomy, as a branch of biology, comprises the study and organization of the tooth as an isolated entity and as an integrant of both the dental and the masticatory systems[2]. It plays a vital role in enriching the students about the basic morphology of teeth so that as they mature into dentists, they will be confident practitioners and will be highly proficient. From the above obtained results it is seen that most students are confused between the surfaces of the teeth when asked to identify from a picture. It was also seen that most students had difficulty in distinguishing between mandibular and maxillary teeth. Nearly $40 \%$ of the students who attempted the questionnaire seemed to be rather unclear about their concepts.
Though Dental Anatomy is a part of first year curriculum in most dental colleges in India, it is actually continued in majority of the course duration in colleges abroad. This lays emphasis on just how important dental anatomy is and especially tooth morphology is. To understand the various dental procedures one must first be proficient in tooth identification, as it lays the foundation for them to further learn and understand the wide curriculum that follows.

\section{CONCLUSIONS}

From the above drawn results, it is observed that most students face a difficulty in identifying the anterior teeth on the basis of characteristic features and confuse them with other anterior teeth showing close similarity. As dental anatomy is a vital subject for understanding tooth morphology which plays an important aspect for having a clear and confident practice. To avoid such difficulties or confusions, it is advised to draw diagrams or use dentulous casts of the dentition whilst studying, as this helps the students to register the important features such as landmarks, the different aspects and surfaces, etc. It also advised to create a flowchart or tabulate the chronological order of teeth on the basis of eruption sequence as this will help remember not only the chronology but also the time of eruption.

\section{References:}

1. Patil S, Sowmya SV, Rao RS, Raj T. Knowledge, attitude and practice of tooth morphology among dental students. J Adv Clin Res Insights 2015;2; 124130.

2. Siéssere, Selma, Vitti, Mathias, Sousa, Luiz Gustavo de, Semprini, Marisa, \& Regalo, Simone Cecílio Hallak. (2004). Educational material of dental anatomy applied to study the morphology of permanent teeth. Brazilian Dental Journal, 15(3), 238-247

3. Stanley J.Nelson DDS MS: Wheelers Dental Anatomy, Physiology and Occlusion.

4. Sampath Kumar P. Dental Anatomy and Tooth Morphology. 1st ed. New Delhi: Jaypee Publications; 2004.

5. Scott, J. H., \& Symons, N. B. (1961). Introduction to Dental Anatomy. Academic Medicine, 36(7), 843.

6. Jankelson, B. (1955). Physiology of human dental occlusion. The Journal of the American Dental Association, 50(6), 664-680.

7. Brand, R. W., Isselhard, D. E., \& Satin, E. (2013). Anatomy of orofacial structures: a comprehensive approach. Elsevier Health Sciences.

8. Pécora, J. D., Woelfel, J. B., Sousa Neto, M. D., \& Issa, E. P. (1991). Morphologic study of the maxillary molars. Part I: external anatomy. Braz Dent J, 2(1), 4550.

9. Short, M. J., \& Levin-Goldstein, D. (2016). Head, Neck and Dental Anatomy. Cengage Learning.

10. Fanning, E. A., \& Brown, T. (1971). Primary and permanent tooth development. Australian dental journal, 16(1), 41-43. 